\title{
ESTADO DEMOCRÁTICO DE DIREITO: ASPECTOS CONSTITUCIONAIS DA JUDICIALIZAÇÃO DA SAÚDE E PRINCÍPIO DA IGUALDADE
}

\author{
Riva Sobrado de Freitas ${ }^{1}$ \\ Felipe Dalla Vecchia ${ }^{2}$
}

RESUMO: O direito à saúde na Constituição Federal Brasileira de 1988 consiste na possibilidade de (a) exigir-se do Estado ou de terceiros a abstenção de atos passíveis de originar moléstias; e de (b) requerer prestações estatais que visem à promoção da saúde e ao tratamento de doenças. Tendo em vista que o Estado nem sempre espontaneamente efetiva tais direitos, a própria Lei Maior coloca à disposição de seus titulares instrumentos para exigir-se tais prestações, cuja utilização constitui objeto de estudo deste trabalho.

\section{PALAVRAS-CHAVE: judicialização; saúde; constituição}

\section{Democratic right state: constitutional aspects of the judicialization of heath and the equality principle}

\begin{abstract}
The right to health in the 1988 Brazilian Constitution consists in the possibility of (a) demanding from the State or other individuals the stoppage of any act which can cause damage to people's health; and of (b) requiring assistances from the State in order to promote health or cure diseases. Considering that not always these installments come spontaneously from the State, in the Constitution there are official means to make it happen, which will be studied in this composition.
\end{abstract}

KEYWORDS: judicialization; health; constitution

\section{INTRODUÇÃO}

\footnotetext{
${ }^{1}$ Professora assistente-doutora de Direitos Humanos e Direito Constitucional da Universidade Estadual Paulista "Júlio de Mesquita Filho" (UNESP), campus de Franca. Mestre e Doutora pela Pontifícia Universidade Católica (PUC) de São Paulo. Pós-doutora pela Universidade de Coimbra. Pesquisadora-líder do grupo de pesquisa e extensão Constituição e Cidadania (CONSCI), da UNESP - Franca.

2 Bacharelando do $3^{\circ}$ ano em Direito pela Universidade Estadual Paulista "Júlio de Mesquita Filho" UNESP, campus de Franca. Bolsista FAPESP de Iniciação Científica, desenvolvendo o tema "O princípio da igualdade como pressuposto fundamental do Estado Democrático de Direito. Integrante do grupo universitário de pesquisa "Constituição e Cidadania" (CONSCI), da UNESP - Franca. E-mail: f.vecchia@hotmail.com.
} 
Tendo em vista sua crescente ocorrência, o presente trabalho visa analisar os aspectos constitucionais do fenômeno denominado de judicialização da saúde, que consiste no atendimento, via juízos e tribunais, do direito à saúde presente na Constituição Federal Brasileira de 1998, primordialmente com relação ao princípio da igualdade. Para tanto, faz-se necessária a análise preliminar dos contornos do Estado brasileiro, de modo a verificar se sua própria configuração enseja a aludida atuação do Poder Judiciário.

A seguir, o direito à saúde será abordado à luz da categoria de direitos em que se insere, a dos direitos sociais, intimamente relacionados com o citado princípio, aferindo-se sua razão de ser e para que depois se investigue sua positivação constitucional. Por fim, a análise de julgados de tribunais brasileiros revelará a materialização, em determinados casos, do direito à saúde e do princípio da igualdade, a um só tempo, ou da impossibilidade do atendimento ao primeiro, visto que ocasionaria a lesão ao outro.

Assim, encontrar-se-á neste trabalho que, em virtude do caput do artigo primeiro da Constituição Federal Brasileira de 1988, o Brasil constitui-se um Estado Democrático de Direito, configuração que bastaria para revelar o posicionamento do constituinte em prol do ser humano. Investigando-se a atual Lei Maior brasileira, tal inclinação confirma-se, dada a amplitude da tutela dos direitos humanos: especialmente relevante ao presente ensaio, o direito à saúde encontra-se arrolado dentre os direitos sociais do artigo $6^{\circ}$ do aludido documento jurídico-político.

Sua tutela específica tem início no artigo 196, o qual enuncia que "A saúde é direito de todos e dever do Estado, garantido mediante políticas sociais e econômicas que visem à redução do risco de doença e de outros agravos e ao acesso universal e igualitário às ações e serviços para sua promoção, proteção e recuperação", e estende-se até o artigo 200, ao longo dos quais se estabelecem as condições para sua efetivação.

Da maneira como se encontra positivado, o direito à saúde revela duas dimensões igualmente importantes: a primeira delas possibilita exigir-se do Estado e dos demais indivíduos a abstenção de quaisquer comportamentos que se possam revelar danosos à saúde; a outra obriga o Estado a fornecer os meios necessários a sua conservação, promoção e recuperação.

No entanto e infelizmente, desde a promulgação da Constituição, a realidade tem revelado a delicadeza do cumprimento destes dispositivos de teor socializante. Em especial no tocante ao direito à saúde, verifica-se a falta de comprometimento e, em alguns casos 
até mesmo a recusa, por parte do Estado com relação à efetivação de seu rico conteúdo constitucional humanístico.

Ciente da possibilidade de situação configurar-se, o constituinte pôs a disposição dos particulares e das coletividades instrumentos idôneos para compelir o Estado a efetivar os direitos da pessoa humana por ela encerrados, originando-se o fenômeno aludido supra.

Um deles é o mandado de segurança, previsto pelo artigo $5^{\circ}$, incisos LXIX e LXX, pelo qual qualquer pessoa, física ou jurídica, demanda a proteção de direito individual ou coletivo, líquido e certo, lesado ou ameaçado por ação ou omissão de autoridade. Cria-se, destarte, a possibilidade de tornarem-se irrelevantes as condições econômicas, sociais, geográficas, etc. no que diz respeito à efetivação do direito à saúde, vez que o Estado, fica vinculado ao atendimento das prestações estabelecidas pela apreciação do mandamus.

Por seu caráter fundamental e sua atualidade, o tema abordado neste trabalho constitui-se de interesse para toda a sociedade, em especial ao atual ou futuro operador do Direito, visto que, a partir de discussões sobre os papéis do atual Estado brasileiro e sobre a utilização dos denominados remédios constitucionais, confrontam-se dois fundamentais imperativos constitucionais: o princípio da igualdade e o direito à saúde. Trata-se de matéria idônea a suscitar grandes debates, capazes de ampliar as raias do conhecimento jurídico.

\section{O ESTABELECIMENTO DO ESTADO DEMOCRÁTICO DE DIREITO NO BRASIL E A RESPONSABILIDADE ACERCA DA EFETIVAÇÃO DOS DIREITOS FUNDAMENTAIS}

Assim como todas as demais manifestações humanas, os Estados são dotados de historicismo. Isto significa que a conceituação, a caracterização, a organização e as manifestações de tais entes políticos, bem como as maneiras pelas quais se relacionam com os indivíduos que abrigam e com outros Estados, coadunam-se com as condições ditadas, interna ou externamente pelo contexto histórico, o que revela insofismável influência sobre a maneira como se dá a tutela dos direitos considerados fundamentais.

Deste modo, a configuração da República Federativa do Brasil como um Estado Democrático de Direito, conforme enuncia o caput do artigo $1^{\circ}$ de sua Constituição 
Federal $^{3}$, constitui-se como resultado de anseios internos e influxos externos, os quais escancararam a necessidade de o Estado adotar um posicionamento de maior envolvimento com as necessidades da população que habita seu território e com a efetivação de seus direitos constitucionais.

A partir da experiência Liberal restava evidenciada a necessidade de reatribuir ao Estado um papel ativo no estabelecimento dos rumos da política, economia e sociedade, almejando a progressão da igualdade meramente formal e tipicamente liberalista, para uma igualdade material, característica dos Estados Sociais surgidos no início do século XX.

Nesta, já não se generalizavam as necessidades dos indivíduos de modo a tutelá-las por uma universalizante estipulação de direitos. Contrariamente, a substancialização da igualdade se pode atingir única e paradoxalmente pela discriminação, identificando-se anseios e necessidades específicas a determinados grupos sociais e oferecendo, aos mesmos, tratamentos específicos visando satisfazer os direitos conferidos a seus integrantes.

Abandonam-se as vãs declarações de direitos com pretensão universalizante e passa-se a positivar seu conteúdo em Constituições, revelando-se na busca de uma igualdade factual o caminho para alcançar a efetivação de tais direitos e conferindo ao Estado um papel ativo nesta empreitada. De acordo com Paulo Bonavides (2009):

\section{O homem pisava firme na estrada da democracia e os seus combatentes haviam de prosseguir como efetivamente prosseguiram, determinando a mudança que houve, com o tempo, no sentido das cartas constitucionais, cada vez mais exigentes de conteúdo destinado a fazer valer objetivamente as liberdades concretas e dignificadoras da personalidade humana. (BONAVIDES, 2009, p. 7)}

Lançavam-se ao Estado outros fins, sem, contudo, ignorar-se a contribuição do Estado Liberal de Direito para a configuração de tais Estados Sociais, uma vez que compete ao primeiro a extinção do arbítrio estatal, materializado nas interferências indiscriminadas deste ente político sobre a vida dos particulares.

O reconhecimento e a tutela dos direitos fundamentais passam a constituir, pois, a essência do denominado Estado Social de Direito, de modo que não se pode considerar legítima a proclamação de determinado Estado como tal, se não houver por parte dos

\footnotetext{
${ }^{3}$ Art. 1', CF 1988: "A República Federativa do Brasil, formada pela união indissolúvel dos Estados e Municípios e do Distrito Federal, constitui-se em Estado Democrático de Direito e tem como fundamentos $[\ldots] "$.
} 
Poderes Públicos um efetivo comprometimento com a efetivação dos direitos tidos como fundamentais ao ser humano.

No Brasil, o processo de instituição da configuração estatal em apreço inaugura-se com a Constituição Federal de 1934, sob o influxo primordial da Constituição Alemã de Weimar de 1919. A partir de então, o Estado brasileiro abandona a mera declaração de uma igualdade aritmética e passa a buscar a satisfação dos anseios e necessidades das coletividades, a partir da concretização dos direitos inerentes aos indivíduos (MELLO, 1993, p. 13). E o constante aprimoramento desta configuração de Estado Social culminará no denominado Estado Democrático de Direito (BASTOS, 2004, 163), instituído no Brasil a partir de 1988 pelo artigo primeiro da Constituição Federal Brasileira promulgada neste ano.

Uma visão geral desta novel e atual concepção de Estado no Brasil, se pode aferir do artigo $2^{\circ}$ da Constituição da República Portuguesa, em que se funda em Portugal o Estado de Direito Democrático, in verbis:

Artigo $2^{\circ}$ A República Portuguesa é um Estado de direito democrático, baseado na soberania popular, no pluralismo de expressão e organização política democráticas, no respeito e na garantia de efectivação dos direitos e liberdades fundamentais e na separação e interdependência de poderes, visando a realização da democracia económica, social e cultural e o aprofundamento da democracia participativa.

O Estado Democrático de Direito, destarte, assentaria sua origem e finalidade na conformidade com o Direito manifestado livremente pelo próprio povo (REALE, 1998, p. 2). É dizer, a vontade estatal, para fazer jus a tal configuração, de coincidir com a vontade das coletividades que o habitam. Assim, evidencia-se o empenho estatal de fazer surdir a cidadania e a dignidade humana, resguardadas em direitos e garantias (BONAVIDES, 2009, p. 29) positivados pela Constituição Federal. Conjugados, estes valores, dentre os quais se inclui a saúde, constituem o necessário norteamento do Estado brasileiro no que diz respeito à sua atuação política, econômica e social.

Isso porque conferir cidadania e dignidade humana às coletividades significa conferir às mesmas o conjunto de instrumentos pelos quais podem participar compor da vontade estatal tendo em vista suas necessidades e interesses, e posteriormente, reverter os frutos da materialização desta vontade em proveito da melhoria de suas condições de vida.

Neste sentido, além de objetivos e fundamentos sociais positivados logo em seus primeiros artigos, a Constituição Federal de 1988 elencou em vasto catálogo de direitos 
sociais, de cujo reconhecimento e efetiva materialização não se pode prescindir um Estado instituído como Democrático de Direito (ARAÚJO; NUNES JR., 2007, p. 100). E dentre estas prerrogativas conferidas ao indivíduo, sobreleva-se o direito à saúde cuja necessidade de efetivação revela-se intrínseca ao mencionado modelo de Estado, e de sua responsabilidade.

\section{A SAÚDE COMO UM DIREITO SOCIAL}

A Constituição Federal Brasileira agrupa e classifica os direitos nela positivados tomando como critério seus respectivos conteúdos, isto é a natureza do objeto tutelado. De acordo com tal conteúdo, José Afonso da Silva arrola seis diferentes classificações de direitos fundamentais albergadas pela Lei Maior brasileira (SILVA, 2007, p. 183 e 184), interessando ao presente trabalho aqueles atribuídos ao homem-social, que consistem em direitos que a Constituição Federal Brasileira de 1988 assegura aos indivíduos em suas relações sociais e culturais. Exempli gratia, a saúde, a educação, a seguridade social, dentre outros (SILVA, 2007, p. 183 e 184).

Em âmbito mundial, a primeira Constituição a tutelar tais direitos foi a mexicana de 1917. No Brasil, a inserção de um título sobre a ordem econômica e social na Constituição deu-se sob a influência da Constituição alemã de Weimar, em 1934. A partir de então, as constituições posteriores não mais deixaram de abrigar tal capítulo (SILVA, 2007, p. 285).

\subsection{Conceituação e eficácia constitucional dos direitos sociais e sua relação com o princípio da igualdade}

A Constituição Federal Brasileira de 1988, em seu segundo Título, denominado “Dos Direitos e Garantias Fundamentais", Capítulo II, arrola em seu artigo $6^{\circ}$ os direitos classificados como sociais, in verbis: "são direitos sociais a educação, a saúde, o trabalho, a moradia, o lazer, a segurança, a previdência social, a proteção à maternidade e à infância, a assistência aos desamparados, na forma desta Constituição".

Conforme se pode observar, a Carta Magna brasileira elenca tais direitos, mas não os define, ficando tal empreitada reservada à rica doutrina constitucionalista brasileira. Dentre os mais respeitáveis autores, sobreleva-se a definição de José Afonso da Silva (2007, p. 286 e 287), para quem os direitos sociais "são prestações positivas 
proporcionadas pelo Estado direta ou indiretamente, enunciadas, em normas constitucionais, que possibilitam melhores condições de vida aos mais fracos, direitos que tendem a realizar a igualização de situações sociais desiguais".

A partir da definição do professor da Universidade de São Paulo constata-se que a materialização dos direitos sociais por meio de prestações ativas constitui obrigação de um Estado que, expressamente em sua Lei Maior, caracteriza-se como Democrático de Direito.

Com base na doutrina de J. J. Gomes Canotilho e Vital Moreira (2007, p. 814), tendo-se realizado as necessárias adaptações, faz-se legítimo afirmar que os Poderes Públicos do Estado Brasileiro encontram-se obrigados a respeitar os direitos sociais de todos, atuando positivamente no sentido de garantir a efetivação dos mesmos, como meio a assegurar a participação de todos os grupos sociais no bem-estar da coletividade.

Ademais, tais prestações-obrigações relacionam-se intimamente com a materialização do princípio da igualdade material, adequado ao Estado Democrático de Direito, visto que atender aos imperativos de tais direitos implica na consecução de condições materiais imprescindíveis ao pleno exercício das demais liberdades constitucionalmente reconhecidas.

Neste sentido, manifesta-se também Uadi Lammêgo Bulos (2009, p. 624), quem ensina que finalidade desses direitos reside, justamente, no benefício dos hipossuficientes, com vistas a assegurar-lhes, direta ou indiretamente, o suprimento de suas respectivas condições de desvantagem, a partir da realização da igualdade real.

Prossegue o mencionado professor asseverando que tais prestações qualificam-se como positivas porque devem constituir-se um fazer por parte dos órgãos do Estado, incumbido de realizá-las com vistas à concretização destes direitos, cuja positivação constitucional faz com que se constituam verdadeiros direitos de crédito cuja satisfação se pode exigir do Estado (BULOS, 2009, p. 624).

Abrangendo todas estas facetas dos direitos sociais, fazem-se úteis os ensinamentos de Alexandre de Morais (2006, p. 190), para que os direitos sociais "são direitos fundamentais do homem, caracterizando-se como verdadeiras liberdades positivas, de observância obrigatória em um Estado Social de Direito, tendo por finalidade a melhoria das condições de vida aos hipossuficientes, visando à concretização da igualdade social".

Considerando-se que o parágrafo primeiro do art. $5^{\circ}$ da Constituição Federal Brasileira de 1988 preceitua que "as normas definidoras dos direitos e garantias 
fundamentais têm aplicação imediata", aufere-se que o Estado não pode eximir-se do cumprimento dos direitos sociais atribuindo-lhes o caráter de normas programáticas.

A partir do momento em que tais direitos encontram-se positivados no mencionado documento jurídico-político, a eles confere-se eficácia plena. Conseqüência disso é a possibilidade de, diante da leniência estatal no tocante à materialização do conteúdo de tais normas, as já mencionadas prestações positivas estatais podem ser requeridas por via judicial.

Tais características encontram-se de tal forma intrincadas na Constituição Federal Brasileira que se pode afirmar que, apesar de o contexto internacional apontar para um retrocesso das atribuições estatais, forçando a conformação de tais entes com o neoliberalismo, não há como as funções atribuídas aos mesmos desvencilharem-se do dever de transformação do status quo (SILVA, p. 119), visando-se a equiparação dos indivíduos e coletividades hipossuficientes àqueles ou àquelas de existência mais conforme ao princípio da dignidade da pessoa humana (BONAVIDES, 2009, p. 33).

\subsection{A tutela constitucional do direito à saúde}

Com base em tudo quanto já se expôs até o momento, afere-se que a relação entre a atuação Estatal e o direito à saúde deve assentar-se na responsabilidade do primeiro pela efetivação do segundo, verificada a insuficiência da mera previsão de determinado direito, sem o devido comprometimento com sua realização.

Hodiernamente, entende-se por saúde não somente a ausência de doenças. $\mathrm{O}$ termo estende-se à manutenção do bem-estar físico e mental, de maneira que se possibilitem condições dignas de vida. Desta forma, tal conceito acerca-se também da preservação do meio ambiente, indubitavelmente um pressuposto fundamental para a obtenção das aludidas condições.

Apesar de sua tutela não revelar-se de todo estranha ao Direito Constitucional brasileiro, sua inserção dentre os direitos do homem constitui novidade da atual Lei Maior. Nas precedentes, a inserção da saúde representava tão-somente o comprometimento da administração Pública com o combate às endemias e epidemias (SILVA, 2007, p. 308).

No que diz respeito à Constituição Federal Brasileira de 1988, conforme já se mencionou supra, o direito à saúde situa-se em seu artigo $6^{\circ}$, arrolado dentre os direitos sociais. Bastaria tal inserção constitucional para que o Estado Brasileiro ficasse obrigado a 
reconhecê-lo e respeitá-lo com relação àqueles que habitam seu território, a saber, brasileiros natos e naturalizados ou estrangeiros.

No entanto, mais adiante no mesmo documento político-jurídico o direito à saúde encontra nova inserção, agora no Título VIII, na Seção I do Capítulo II, denominado "Da Seguridade Social". Este termo, conforme consta do artigo 194, refere-se a um "conjunto integrado de ações de iniciativa conjunta dos Poderes Públicos e da sociedade, destinadas a assegurar os direitos relativos à saúde, à previdência e à assistência social”.

O parágrafo único desse mesmo artigo traça os objetivos e princípios que norteiam a organização do atendimento aos direitos da seguridade social, a saber: "I - universalidade da cobertura e do atendimento; II - uniformidade e equivalência dos benefícios e serviços às populações urbanas e rurais; III - seletividade e distributividade na prestação dos benefícios e serviços; IV - irredutibilidade do valor dos benefícios", dentre outros.

Conservar-se tais objetivos e princípios em mente na ocasião do estudo específico dos direitos da seguridade social importa na medida em que a interpretação que se faz de tais direitos não se pode dar de maneira apartada de tais valores (SILVA, 2007, p. 308).

Com relação ao direito à saúde, sua tutela específica encontra-se nos artigos de 196 a 200. Preceitua o primeiro dispositivo mencionado que "a saúde é direito de todos e dever do Estado, garantido mediante políticas sociais e econômicas que visem à redução do risco de doença e de outros agravos e ao acesso universal e igualitário às ações e serviços para sua promoção, proteção e recuperação".

Em suas linhas gerais, o direito à saúde relaciona-se com o direito à vida, com o princípio da dignidade da pessoa humana e também com o princípio da igualdade. Este último evidencia-se pelo trecho do mencionado dispositivo em que se estabelece a saúde como "direito de todos". Com base em José Afonso da Silva, entende-se tal passagem de maneira a afirmar-se que, nos casos de doença, todos, indiscriminadamente, têm direito ao tratamento adequado, consoante o estado atual da ciência médica (SILVA, 2007, p. 308).

A partir do direito à saúde como "dever do Estado", infere-se que, independentemente das condições econômico-financeiras daquele que necessita tê-lo satisfeito, tal deve realizar-se por meio de medidas estatais positivas, fazendo-se jus, inclusive, ao envolvimento estatal com os principais anseios e misteres da sociedade, 
característica do Estado Democrático de Direito em que se constitui a República Federativa do Brasil ${ }^{4}$.

Desse modo, as "políticas sociais e econômicas" que visam constituírem-se em garantias de tal direito, devem provir do Estado. Para tanto, o artigo 198 da Constituição Federal integra "as ações e serviços públicos de saúde" em "uma rede regionalizada e hierarquizada", constituindo "um sistema único", a ser financiado, com base no parágrafo primeiro do artigo 198, "com recursos do orçamento da seguridade social, da União, dos Estados, do Distrito Federal e dos Municípios”, e outras fontes.

Trata-se do Sistema Único de Saúde (SUS), cuja doutrina declara a universalização do acesso à saúde, pretendendo-se garantir à totalidade da população residente no Brasil o acesso integral a partir do simples tratamento ambulatorial até os transplantes de órgãos ${ }^{5}$, independentemente de suas condições financeiras ou localização geográfica (CRUZ, JR.; SARTOR; SOUZA, 2003, p. 229). Regulamenta-o a Lei federal $\mathrm{n}^{\circ} 8.080$ de 19 de setembro, e regulam-no as Portarias $n^{\circ} 2.048$, de 3 de setembro de 2009 e $n^{\circ} 2.230$ de 23 de setembro de 2009, ambas do Ministério da Saúde.

No que diz respeito à extensão da tutela à saúde, o enunciado do referido artigo 196 evidencia duas dimensões. A primeira consiste na busca pela "redução do risco de doenças e outros agravos", semelhante à vertente negativa do direito à protecção da saúde do direito português. Insere-se dentre os direitos de defesa tradicionais, traduzindo-se na possibilidade constitucional de exigir-se do Estado e demais particulares a não realização de quaisquer atos danosos à saúde (CANOTILHO; MOREIRA, 2007, p. 825).

A outra se enuncia pelo "acesso universal e igualitário às ações e serviços", para a promoção, proteção e recuperação da saúde. Corresponde, portanto, à vertente positiva do mencionado direito do constitucionalismo português, explanada por J. J. Gomes Canotilho e Vital Moreira como o direito às medidas e prestações estatais que visem a prevenção e tratamento das doenças (CANOTILHO; MOREIRA, 2007, p. 825).

Com base no exposto até aqui, pode-se asseverar que o Brasil dispõe de rica previsão constitucional do direito à saúde. Contudo, em caráter enfático e específico, alguns dispositivos infraconstitucionais também tutelam tal direito. Trata-se do que se observa, por exemplo, no Estatuto da Criança e do Adolescente, que em seu artigo $4^{\circ}$

\footnotetext{
${ }^{4}$ Para maiores esclarecimentos acerca da configuração estatal da República Federativa do Brasil, consultar item 2, supra.

${ }^{5}$ Disponível em <http://portal.saude.gov.br/portal/saude/cidadao/default.cfm>. Acesso em 30 de março de 2010 .
} 
preceitua ser "dever da família, da comunidade, da sociedade em geral e do poder público assegurar, com absoluta prioridade, a efetivação dos direitos referentes à vida, à saúde, à alimentação, à educação, ao esporte, ao lazer, à profisssionalização, à cultura, à dignidade, ao respeito, à liberdade e à convivência familiar e comunitária" de tal categoria de indivíduos.

\subsection{A realidade acerca da efetivação do direito à saúde no Brasil e o conseqüente fenômeno de sua judicialização}

Pela análise do texto constitucional aufere-se a boa vontade do constituinte ao fundar o Sistema Único de Saúde (SUS), estabelecendo seus objetivos e princípios e pretendendo conferir-lhe plena eficácia e amplo alcance social. Tanto que, nos termos do parágrafo primeiro do artigo 199 da Constituição brasileira, a criação de órgãos privados de saúde assumiria caráter de complementação ao órgão público.

Neste sentido João Benjamin da Cruz Jr., Vicente Volnei de Bona Sartor e Maria de Lourdes Souza (2003) afirmam que:

[...] no âmbito da saúde pública, na atual sociedade pluralista, admitem-se diferentes valores e normas nas práticas dos serviços de saúde, entre eles, a vida humana, a dignidade da pessoa humana, a qualidade de vida, a produtividade, a justiça, os direitos individuais, o consumo e o prazer. Como princípios, pode-se lembrar a autonomia a beneficência, a não-maleficência, a justiça, a honestidade, a veracidade, a privacidade, a utilidade e o respeito à vida. (CRUZ JR.; SARTOR; SOUZA, 2003, p. 215)

No entanto, infelizmente a prática nem sempre revela a materialização destas louváveis intenções, tampouco a consecução de tais diretrizes ou a observância aos princípios posto. Tal comprova-se por más condições de hospitais no que se refere às possibilidades de oferecer-se um atendimento de qualidade; demora nos procedimentos de diagnóstico e tratamento; discriminação no atendimento, priorizando-se apadrinhados, amigos ou indicados, ou então a observância estrita da ordem de chegada, sem contemplarem-se os casos de necessitam de atendimento emergencial; descaso com os pacientes, prioridades de qualquer instituição de saúde, etc. (DINIZ, 2002, p. 150 e 151).

Justiça seja feita: não há dúvidas de que, desde sua criação com o advento da Constituição Federal Brasileira de 1988, o sistema público de saúde muito fez para a população brasileira, e suas possibilidades ampliam-se cada vez que recebe 
aprimoramentos. Contudo, ainda permanece distante de traduzir-se no ideal sistema constitucional.

Isto porque, conforme revela a recente História nacional, pretendeu-se estabelecer um projeto avançado e moderno de Brasil priorizando-se o desenvolvimento econômicoindustrial. Em um paradoxo quase que incompreensível, relegavam-se a um segundo plano os âmbitos social e o político, sem conferir-lhes tratamento correspondente ao do setor produtivo. Na mesma linha de raciocínio, diz-se que o desenvolvimento social e, portanto, o acesso da grande maioria da população aos bens sociais primários, tornou-se um subproduto do desenvolvimento econômico. Numa metáfora social, milhões de pessoas foram excluídas do acesso aos bens primários produzidos pelo Estado, principalmente da saúde universal (CRUZ JR.; SARTOR; SOUZA, 2003, p. 215).

Nesse contexto, a leniência do Estado brasileiro com relação à efetivação universal do direito à saúde, acaba por desconfigurar o Estado Democrático de Direito, revelando-o mais adequado ao modelo de Estado Liberal, em que o distanciamento estatal com as questões sociais suscita a desigualdade. É dizer, a carência de políticas públicas de larga abrangência social faz com que os serviços de saúde de qualidade tornem-se privilégio da parcela da população brasileira dotada de satisfatórias condições econômico-financeiras, constatação negativa e incompatível com a vida, dignidade humana e igualdade (CRUZ JR.; SARTOR; SOUZA, 2003, p. 223).

Assim, se por um lado o Brasil situa-se entre os maiores produtores de riqueza do mundo, por outro aparece dentre os piores em matéria de saúde, justamente por situar os reclamos e misteres sociais abaixo dos econômicos, preferindo-se reinvestir em economia a investir em desenvolvimento humano. Diante dessa realidade, a administração Pública necessita repensar a eficácia dos princípios e diretrizes que regem a saúde pública (CRUZ JR.; SARTOR; SOUZA, 2003, p. 228).

Verbi gratia, em virtude das circunstâncias apresentadas supra revela-se impossível o exercício do princípio da autonomia da vontade, pelo qual o indivíduo que necessita de cuidados médico-hospitalares pode opor-se a determinado tratamento, optando por outro, menos rigoroso ou mais adequado segundo seus valores, de aceitar ou não uma intervenção cirúrgica, de mudar de médico ou hospital, etc.

Em completo detrimento da autodeterminação, verifica-se o condicionamento da vontade do indivíduo, tolhido de suas escolhas frente às condições adversas apresentadas pela tutela pública do direito à saúde. 
Tendo em vista as considerações até o presente ponto, pode-se pretender a retirada de toda a eficácia que nele conferiu-se ao direito à saúde, situando-o dentre as normas de conteúdo programático, mas proceder desta forma significa conformar-se com a inconstitucionalidade. $\mathrm{O}$ direito à saúde, bem como a totalidade dos direitos sociais, existe, encontra-se positivado na Constituição Federal Brasileira e, portanto, goza de aplicabilidade imediata.

Neste sentido, assevera José Afonso da Silva (2007, p. 88) em sua obra Aplicabilidade das normas constitucionais, que "a orientação doutrinária moderna é no sentido de reconhecer eficácia plena e aplicabilidade imediata à maioria das normas constitucionais, mesmo a grande parte daquelas de caráter sócio-ideológico, as quais até bem recentemente não passavam de princípios programáticos".

Da mesma forma, Ricardo Cunha Chimenti, Fernando Capez, Marcio Fernando Elias Rosa e Marisa Ferreira dos Santos (2006, p. 128) entendem que os direitos sociais abrigados pela Constituição representam mais que meras normas programáticas, verdadeiros direitos subjetivos do indivíduo, oponíveis ao Estado para que tal ente forneça as prestações diretas ou indiretas necessárias à efetivação dos mesmos. E complementam tal idéia, afirmando que a satisfação de tais direitos constitui pressuposto para a efetivação do princípio da dignidade da pessoa humana.

Felizmente, senso do constituinte não se limitou a traçar satisfatórias diretrizes e princípios para os direitos sociais albergados pela Constituição brasileira, mas também o habilitou a prever a possibilidade de o Estado, por quaisquer que sejam as razões, não atuar, espontaneamente, no sentido da efetivação dos mesmos.

Por isso disponibilizou na própria constituição, instrumentos de que se podem valer os particulares para terem materializados seus direitos. Trata-se dos denominados remédios constitucionais, meios aptos a provocar a intervenção das autoridades competentes, visando à correção de ilegalidade e abuso de poder quando detrimentosos aos direitos e interesses individuais (SILVA, 2007, p. 442). São, por exemplo, o habeas corpus, o habeas data, o mandado de injunção, o mandado de segurança, etc.

E a utilização de algum destes instrumentos de caráter processual e constitucional, apto a efetivar o direito à saúde por intermédio de determinação do Poder Judiciário, provoca o surgimento de um fenômeno denominado judicialização do mencionado direito. Significa a extensão da competência de juízos e tribunais para o atendimento de demandas 
que, apesar de constitucionais, parecem fugir a sua área de atuação, como o caso do direito em apreço neste trabalho.

Com relação a tais instrumentos, a jurisprudência revela que, quando reunidos os elementos necessários a produzir uma decisão de mérito favorável ao impetrante, o mandado de segurança individual constitui instrumento judicial apto para a consecução do atendimento estatal às necessidades envolvendo o direito à saúde, e ao mesmo dirigem-se as asseverações a partir deste ponto.

Recentemente regulado pela Lei 12.016 de 07 de agosto de 2009, tal instrumento já constava do artigo $5^{\circ}$, inciso LXIX da Constituição Federal Brasileira, assim enunciado: “conceder-se-á mandado de segurança para proteger direito líquido e certo, não amparado por 'habeas-corpus' ou 'habeas-data', quando o responsável pela ilegalidade ou abuso de poder for autoridade pública ou agente de pessoa jurídica no exercício de atribuições do Poder Público".

Em seguida, serão analisados os aspectos constitucionais de jurisprudências em que houve a utilização desse instrumento, no tocante à efetiva materialização do direito e de possíveis lesões ao princípio constitucional da igualdade.

\section{ANÁliSE JURISPRUDENCIAL: A EFETIVAÇÃO DO DIREITO À SAÚDE FRENTE AO PRINCÍPIO DA IGUALDADE}

Sabe-se que o Liberalismo aplicado à configuração do Estado e às relações interparticulares mostrou-se um fator de agravamento das desigualdades, uma vez que, diante da falta de atuação estatal no sentido de suprir as necessidades dos hipossuficientes, estes tinham seu desenvolvimento obstado por aqueles que se bastavam em si próprios.

No Brasil, os ideais liberalistas verificam-se na caracterização formal das instituições dos períodos considerados por Paulo Bonavides (2009, p. 361 e ss.) a primeira e segunda fases do constitucionalismo pátrio, reguladas, respectivamente, pelas Constituições de 1824 e 1891. Prevalecia em tais cartas uma idéia de igualdade meramente formal ou de iure, cuja materialização consistia em tão-somente garantir-se a todos o mesmo ponto de partida (BOBBIO, 1997, p. 30) para o desenvolvimento econômico, social e político individual.

O problema desta concepção reside no fato de que a lei, ao conceder os mesmos direitos de forma genérica a todos os indivíduos, terminava por ignorar suas prerrogativas ou 
desvantagens, naturais ou sociais, de materialização de direitos (BOBBIO, 1997, p. 23), de modo que, a contrario sensu, pois, a igualdade formal revelou-se fonte de acentuadas desigualdades.

A partir da experiência insatisfatória dos Estados Liberais de Direito, revela-se a necessidade de tutelar-se uma igualdade capaz de efetivamente produzir efeitos na realidade, uma igualdade material, pois, ou de facto. Isso se insere no constitucionalismo brasileiro a partir de sua terceira fase denominada por Paulo Bonavides (2007, p. 336) de constitucionalismo do Estado Social (BONAVIDES, 2009, p. 366), cuja inauguração deu-se sob o influxo primordial da Constituição Alemã de Weimar de 1919 e que, após alguns aprimoramentos e retrocessos prevalece até o presente.

Destarte, a igualdade que se buscará pela investigação do tratamento jurisprudencial da saúde consiste, justamente, na igualdade material, a qual, segundo Celso Antônio Bandeira de Mello, se pode obter mediante um tratamento igual aos iguais e desigual aos desiguais, na justa medida em que se desigualam (MELLO, 1993, p. 21).

O primeiro caso a se estudar neste trabalho consiste numa impetração de mandado de segurança contra a Secretaria de Saúde do Estado do Rio Grande do Sul, objetivando-se que este concedesse a menor impúbere a quem acometia grave e rara doença, denominada fenilcetonúria, os medicamentos necessários ao seu tratamento, fabricados exclusivamente nos Estados Unidos e na Suíça. Em recurso extraordinário, tal ente político almeja legitimar o não atendimento à prestação solicitada $^{6}$, aludindo, em sua defesa, que inexiste o direito líquido e certo, referindo-se, aparentemente, ao próprio direito à saúde. Tanto que em seguida, questiona a aplicabilidade do artigo 196 da Constituição Federal Brasileira de 1988, taxando-o de indireta e reduzida.

Conforme já se teve oportunidade de discorrer neste trabalho, hodierna orientação doutrinária aponta para o reconhecimento de plena eficácia e aplicabilidade imediata à maioria das normas constitucionais, inclusive àquelas que prevêem direitos aparentemente carentes de complementação por outros dispositivos normativos (SILVA, 2008, p. 88).

Não cabe, pois, o afastamento do writ com base em falta de eficácia constitucional. Trata-se, pois, de direito líquido e certo, tendo em vista que, além da Constituição Federal, também a Constituição do Estado do Rio Grande do Sul reconhece, em seu art. 241, caput, que "a saúde é direito de todos e dever do Estado e do Município, através de sua promoção, proteção e recuperação”.

Ademais, por se tratar de pessoa menor, sua pretensão encontra-se amparada pelo Estatuto da Criança e do Adolescente, que em seu artigo $4^{\circ}$ atribui aos familiares, à

\footnotetext{
${ }^{6}$ BRASIL, STF, RE 195192, Rel. Min. Marco Aurélio, D.J. 31 mar. 2000.
} 
comunidade, à sociedade em geral e ao Poder Público o dever de assegurar, com absoluta prioridade, a efetivação de determinado direitos do menor, dentre os quais o direito à saúde.

Cabe somente exigir-se a comprovação da efetiva existência da doença a acometer o recorrido, a qual se satisfez, restando constatada a enfermidade rara e possivelmente danosa à saúde e ao desenvolvimento do menor. Em virtude disso, cumpre-se o requisito da ameaça de dano ao direito, já reconhecidamente líquido e certo.

Quanto ao ato de autoridade, alega o ente público não se eivar de ilegalidade ou abuso de poder, vez que o pedido de fornecimento de tais medicamentos não se havia se constatado em âmbito administrativo. Independentemente de tal fato, não resta afastada a obrigatoriedade do Estado com relação ao cumprimento de suas funções, adequadas, inclusive, ao Estado Democrático de Direito de que reveste-se a República Federativa do Brasil como um todo.

Restando atendidos todos os requisitos para o acolhimento de pretensão por intermédio do mandado de segurança, o pedido do menor impúbere recebeu acolhida, ficando o órgão de saúde do Estado do Rio Grande do Sul compelido a fornecer-lhe os medicamentos necessários ao tratamento.

Constata-se, neste caso, a utilização do mandamus como instrumento da igualdade material, vez que sua utilização resultou na obrigatoriedade de o órgão estatal fornecer ao menor fenilcetonúrico as prestações que iam compensar sua hipossuficiência econômica para a aquisição dos medicamentos importados, sabidamente caros, bem como as desvantagens naturalmente possuídas, por meio de um tratamento que lhe devolva a saúde.

Em outro caso, apreciado pelo Tribunal de Justiça do Estado de São Paulo, foi negado o provimento do recurso que almejava a concessão de prioridade na fila de transplantes ${ }^{7}$. Em tal caso aprecia-se mais que somente a configuração ou não do caso concreto com a obrigatoriedade estatal de tutela urgente ao direito à saúde. Aprecia-se um conflito entre tal direito e o princípio da igualdade.

Sabe-se que o solicitante da tutela é portador de doença renal crônica, apresentando, pois, estado de saúde suficientemente grave para ensejar sua inserção na fila única de transplantes. No entanto, constatou-se no aludido enfermo condições que justificassem a concessão de prioridade na mencionada fila, integrada por indivíduos com igualmente desfavoráveis condições de saúde.

\footnotetext{
${ }^{7}$ BRASIL, TJ-SP, Apelação Cível no 735963 5/7-00. Rel. Des. Paulo Dimas Mascaretti. 09 abr. 2008.
} 
A propósito, a autoridade contra quem impetrou-se o mandamus ressaltou a inexistência, ao menos nos autos, de recomendação médica que sugerisse a urgência do procedimento, habitualmente concedida a pacientes que não dispõe de condições para a realização da hemodiálise.

Apesar de penosa, a decisão do ilustre Magistrado merece louvor, tendo em vista não somente o atendimento ao princípio constitucional da igualdade, mas a toda a sociedade, verdadeira base em que se deve assentar a interpretação de tal princípio, sob pena de contaminá-lo com irremediável falta de razão de ser.

O fundamento para tal convencimento reside no fato de que a concessão da pretendida prioridade a determinada pessoa que não apresentasse maior gravidade de seu quadro frente àqueles que compartilham da mesma enfermidade significaria voltar-se um tratamento desigual para pessoas em iguais condições, uma afronta ao princípio em apreço.

Pelo fato de a impossibilidade da priorização para o recebimento do enxerto não resultar de comportamento ativo ou omissivo da autoridade competente, inexiste ilegalidade ou abuso de autoridade em sua conduta, restando descabido o atendimento aos reclamos levados à apreciação do Poder Judiciário por intermédio do mandado de segurança.

Novamente e ao contrário do que se possa pensar, igualdade que se materializou com a referida decisão provém não do próprio tratamento homogeneizado de todos os integrantes da fila de transplantes de rim, mas da não distribuição em categorias distintas das pessoas semelhantes sob o aspecto considerado, atendendo aos fundamentos do Estado Democrático de Direito em vigor no Brasil.

$\mathrm{Na}$ própria fundamentação do magistrado faz-se referência a uma priorização a determinados componentes da aludida fila, a qual combina o critério cronológico com o tipo sanguíneo apresentado pelo candidato ao transplante.

Havendo a disponibilidade do órgão para o transplante, mas não havendo sua compatibilidade sanguínea com o primeiro da fila, aquele que ostentar a menor posição na fila e apresentar tal compatibilidade será beneficiado pelo enxerto. Pelos motivos contrários que fundamentaram a negação do pedido em questão, adéqua-se tal critério de priorização aos imperativos da igualdade material.

\section{CONCLUSÃO}


Nos primeiros escritos deste trabalho analisou-se a atual configuração de Estado no Brasil, com vistas tornar possível a confrontação das reais condições políticas de efetivação dos direitos constitucionais. A partir disso, constatou-se que, apesar de sua responsabilidade, as políticas estatais para a efetivação dos direitos considerados fundamentais aos indivíduos demonstraram-se, em geral, desanimadoras, restando verificada a falta de comprometimento ou mesmo a recusa estatal neste sentido, situação que se torna ainda mais reprovável se auferida em um contexto de Estado Democrático de Direito, como o vigente no Brasil.

Sabe-se, no entanto, que o constituinte de 1988, demonstrando-se atento à experiência constitucional brasileira, não deixou desarmados os indivíduos e as coletividades frente à inércia Estatal, colocando à disposição dos mesmos os remédios constitucionais, aptos a compelir o Estado a satisfazer suas atribuições constitucionais.

Tendo-se aferido os contornos da atual configuração do Estado brasileiro, afere-se a necessidade de atuação do Poder Judiciário, mesmo que subsidiariamente, por meio dos mencionados instrumentos, de modo a conferir materialidade aos comandos constitucionais e à própria configuração do Estado brasileiro. No caso especificamente apresentado, este fenômeno denomina-se judicialização da saúde.

O prosseguimento nos estudos permite aferir que tanto a utilização quanto a apreciação do mandado de segurança, meio apto a pleitear, junto ao mencionado Poder, a efetivação do direito constitucional à saúde, exigem prudência e cautela por parte do operador do Direito, sob pena de proporcionar-se a desigualdade ao invés do atendimento eficaz e satisfatório dos reclamos constantes do mandamus, desconfigurando-se o próprio Estado brasileiro, em cuja essência reside o princípio da igualdade.

Cumpre salientar, ainda, que não se pode adotar a utilização de tais remédios como regra, fazendo que recaia a responsabilidade acerca da concretização dos direitos constitucionalmente previstos ao Poder Judiciário, atribuindo, ao mesmo, competências originariamente da Administração Pública.

Acontecimentos assim deveriam dar-se em caráter absolutamente excepcional à natural e espontânea efetivação estatal dos direitos fundamentais. Para tanto, urge que se progrida da fase da programaticidade para a do reconhecimento de eficácia e da efetivação dos conteúdos socializantes constitucionais. Tal faz-se possível somente mediante profunda mudança de mentalidade, no sentido de buscar-se a plena caracterização do 
Estado brasileiro como Democrático de Direito. Consoante assevera Uadi Lammêgo Bulos (2009, p. 625):

Surge então a importância de repensar o papel que a normatividade das constituições contemporâneas representa diante do caráter jurídico das normas dependentes de regulamentação legislativa, bem como a efetividade delas no cenário constitucional dos Estados. Isso tem que ver com os direitos sociais, nem sempre cumpridos em razão do caráter restritivo, e até limitado, presente em sua configuração (BULOS, 2009, p. 625).

Passar-se dos programas de ação futura, assentados em normas de eficácia contida ou limitada, para a criação das condições necessárias à efetivação dos direitos fundamentais ricamente distribuídos pela atual Constituição Federal Brasileira significa não só a plena conformação da República Federativa do Brasil como legítimo Estado Democrático de Direito como também o respeito, a consideração e o atendimento dos anseios, reclamos e misteres de toda a sociedade brasileira.

\section{REFERÊNCIAS BIBLIOGRÁFICAS}

ARAÚJO, Luiz Alberto David; NUNES JR., Vidal Serrano. Curso de direito constitucional. 11. ed. São Paulo: Saraiva, 2007.

BARROSO, Luís Roberto. Interpretação e aplicação da constituição: fundamentos de uma dogmática constitucional transformadora. 5. ed. São Paulo: Saraiva, 2003.

O direito constitucional e a efetividade de suas normas: limites e possibilidades da constituição brasileira. 5. ed. Rio de Janeiro: Renovar, 2001.

BASTOS, Celso Ribeiro. Curso de teoria do estado e ciência política. 6. ed. São Paulo: Celso Bastos Editora, 2004.

BOBBIO, Norberto. Igualdade e liberdade. 2. ed. Rio de Janeiro: Ediouro, 1997.

BONAVIDES, Paulo. Curso de direito constitucional. 23. ed. São Paulo: Malheiros, 2009.

1972.

Do estado liberal ao estado social. 3. ed. São Paulo: Fundação Getúlio Vargas,

BULOS, Uadi Lammêgo. Curso de direito constitucional. 3. ed. São Paulo: Saraiva, 2009. 
CANOTILHO, Joaquim José Gomes; MOREIRA, Vital. Constituição da república portuguesa anotada. 4. ed. Coimbra: Coimbra Editora, 2007.

CAPEZ, Fernando; CHIMENTI, Ricardo Cunha; ROSA, Marcio Fernando Elias; SANTOS, Marisa Ferreira dos. Curso de direito constitucional. São Paulo: Saraiva, 2006.

GONÇALVES, Kildare. Direito Constitucional. 11. ed. Belo Horizonte: Del Rey, 2005.

CRUZ JR., João Benjamin da; SARTOR, Vicente Volnei de Bona; SOUZA, Maria de Lourdes de. Humanismo, estado brasileiro e saúde pública. In: MEZZAROBA, Orides (org.). Humanismo latino e estado no Brasil. Florianópolis: Fundação Boiteux, 2003.

DINIZ, Maria Helena. O estado atual do biodireito. 2. ed. São Paulo: Saraiva, 2002.

GARCEZ, Sérgio Matheus. O novo direito da criança e do adolescente. Campinas: Alínea, 2008.

HOBBES, Thomas. Leviatã. São Paulo: Martin Claret, 2006.

MELlO, Celso Antônio Bandeira de. Conteúdo Jurídico do Princípio da Igualdade. 3. ed. São Paulo: Malheiros editores, 1993.

MEIRELLES, Hely Lopes. Mandado de segurança, ação popular, ação civil pública, mandado de injunção, habeas data. São Paulo: Revista dos Tribunais, 1989.

MORAES, Alexandre de. Curso de Direito Constitucional. 19. ed. São Paulo: Atlas, 2006

NUNES, Luiz Antonio Rizzato. Manual da Monografia Jurídica. 7. ed. São Paulo: Saraiva, 2009.

REALE, Miguel. O estado democrático de direito e o conflito das ideologias. São Paulo: Saraiva, 1998.

ROUSSEAU, Jean-Jacques. Do contrato Social. São Paulo: Martins Fontes, 2001.

SILVA, José Afonso da. Curso de direito constitucional positivo. 31. ed. São Paulo: Malheiros, 2007.

Aplicabilidade das normas constitucionais. 7. ed. São Paulo: Malheiros, 2008.

VIEIRA, Oscar Vilhena. Direitos fundamentais: uma leitura da jurisprudência do STF. São Paulo: Malheiros, 2006.

<http://portal.saude.gov.br/portal/saude/cidadao/default.cfm>. Acesso em 30 de março de 2010. 